WILEY-VCH

"This is the peer reviewed version of the following article: Angew. Chem. Int. Ed. 2018, 57 (42), 13735-13747, which has been published in final form at DOI: 10.1002/anie.201805009. This article may be used for non-commercial purposes in accordance with Wiley Terms and Conditions for Self-Archiving published at http://olabout.wiley.com/WileyCDA/Section/id-820227.html." 


\section{MINIREVIEW}

\section{Frontispiece picture:}

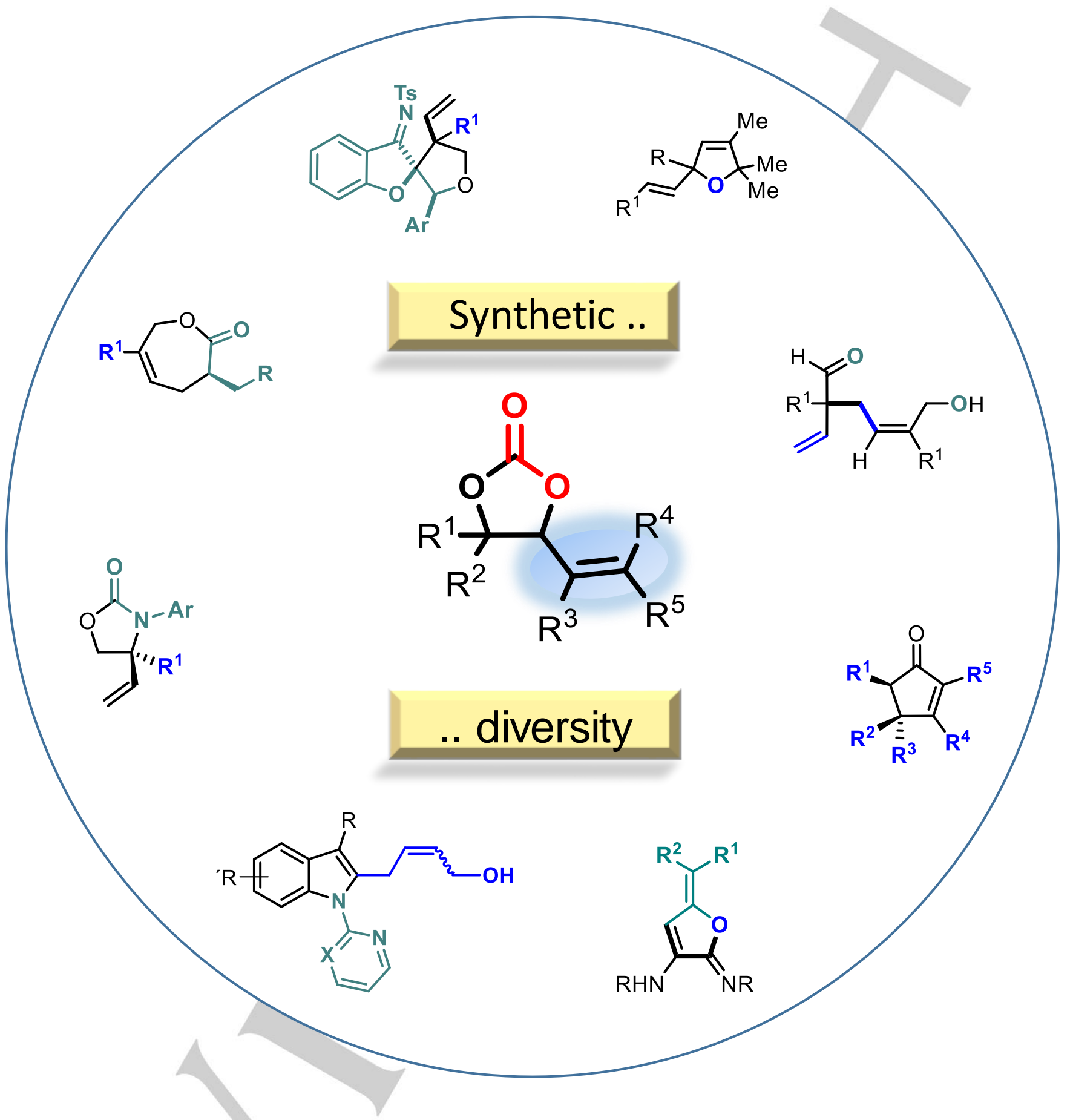




\title{
Catalytic Transformations of Functionalized Cyclic Organic Carbonates
}

\author{
Wusheng Guo, ${ }^{*[a]}$ José Enrique Gómez, ${ }^{[b][c]}$ Àlex Cristòfol, ${ }^{[b][c]}$ Jianing Xie, ${ }^{[b][c]}$ and Arjan W. Kleij ${ }^{*[b][d]}$
}

\begin{abstract}
Functionalized cyclic organic carbonates and related heterocycles have emerged as highly versatile heterocyclic substrates for ring-opening and decarboxylative catalytic transformations allowing for the development of new stereoand enantioselective $\mathrm{C}-\mathrm{N}, \mathrm{C}-\mathrm{O}, \mathrm{C}-\mathrm{C}, \mathrm{C}-\mathrm{S}$ and $\mathrm{C}-\mathrm{B}$ bond formation reactions. Transition metal mediated conversions have only recently been rejuvenated as powerful approaches towards the preparation of more complex molecules. This minireview will highlight the potential of cyclic carbonates and structurally related heterocycles with a focus on their synthetic value and the mechanistic manifolds that are involved upon their conversion.
\end{abstract}

cyclic organic carbonates • decarboxylative couplings • heterocycles $\bullet$ homogeneous catalysis $\bullet$ transition metal catalysis

\section{Introduction}

Recycling of carbon dioxide into value-added organic molecules and materials has received widespread attention among the chemical communities. ${ }^{[1]}$ Among the most studied transformations that take advantage of the cheap, accessible and renewable nature of $\mathrm{CO}_{2}$ as a carbon feedstock is its [3+2] cycloaddition reaction with oxiranes affording cyclic organic carbonates. ${ }^{[2]}$ These oxygen-containing heterocycles have a long history, and the development of new, more sustainable synthetic approaches and applications has been an ongoing endeavor. ${ }^{[3]}$ Whereas conventionally these heterocyclic scaffolds found use as nonprotic solvents, ${ }^{[4]}$ precursors to polycarbonates and related polymers, ${ }^{[5]}$ electrolytes ${ }^{[6]}$ and as intermediates towards commodity chemicals such as ethylene glycol, ${ }^{[7]}$ recent trends show a paradigmatic shift to their use as starting materials for more complex organic targets.

Of vital importance to the exploration of post-synthetic transformations that involve cyclic carbonates is the presence of suitable functionality. In this regard, in the last decade several

[a] Prof. Dr. W. Guo, Center for Organic Chemistry, Frontier Institute of Science and Technology (FIST), Xi'an Jiaotong University, Xi'an 710045, China

[b] J. E. Gómez, À. Cristòfol, J. Xie, Prof. Dr. A. W. Kleij, Institute of Chemical Research of Catalonia (ICIQ), the Barcelona Institute of Science and Technology, Av. Països Catalans 16, 43007, Tarragona, Spain

[c] Universitat Rovira i Virgili, Departament de Química Analítica I Química Orgànica, c/Marcel.lí Domingo, 1, 43007 Tarragona, Spain

[d] Prof. Dr. A. W. Kleij

Catalan Institute of Research and Advanced Studies (ICREA), Pg. Lluís Companys 23, 08010 Barcelona, Spain E-mail:wusheng.guo@mail.xitu.edu.cn; akleii@iciq.es research teams communicated on new metal- and organocatalyst based strategies focusing on the synthesis of more elaborate and challenging compounds from both epoxides and oxetanes. ${ }^{[8]}$ More recently, also epoxy alcohols have shown to offer new potential to construct more complex and functional cyclic carbonates ${ }^{[9]}$ through substrate controlled catalytic approaches that complement the benchmark coupling reactions between oxiranes and $\mathrm{CO}_{2}$.

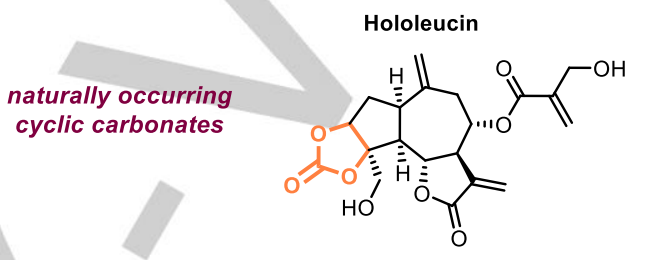

synthetic cyclic carbonates

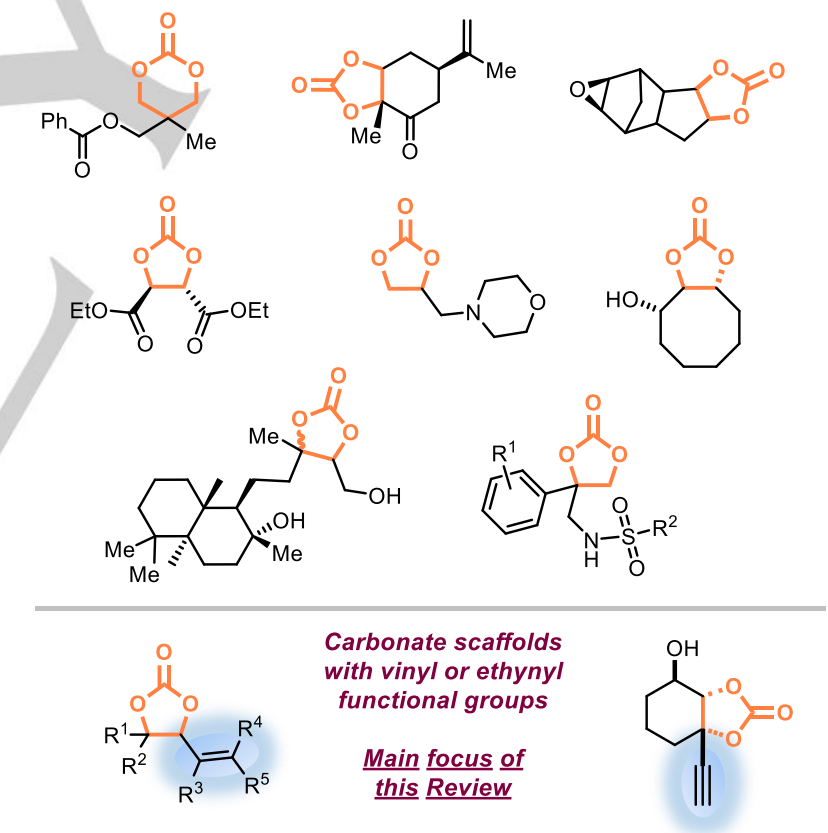

Figure 1. A naturally occurring cyclic carbonate (Hololeucin, top), examples of synthetic cyclic carbonates (middle) and key functionalities for transition metal mediated transformation of these versatile heterocycles (below).

Highly substituted cyclic carbonate rings are frequently encountered in natural compounds, for example in Hololeucin (see Figure 1). A comprehensive review describing the different types of natural organic carbonates, and their biological origin and properties was recently disclosed by Yue and co-workers. ${ }^{[10]}$ The advances made in synthetic cyclic carbonate chemistry have allowed to (partially) mimic the structural complexity of biologically 
occurring cyclic carbonates. Additionally, the significant progress in the preparation of these heterocycles also has provided easy access to synthetically useful vinyl- and alkyne-based cyclic carbonates (Figure 1, below). These specific carbonate examples have enabled new transformations that go beyond classical organic synthesis using cyclic carbonates as substrates. The vinyl-substituted cyclic carbonates (VCCs) can be regarded as allylic surrogates upon decarboxylation, and as such provide reactive intermediates for Tsuji-Trost alkylations, ${ }^{[11]}$ whereas the alkynyl carbonates should facilitate an easy entry into propargylic substitution chemistry. ${ }^{[12]}$

This minireview will present the latest developments, discoveries and opportunities that have arisen in the area of decarboxylative functionalization of mostly cyclic carbonates using predominantly transition metal catalysis. As a prelude to this, the review will first summarize catalytic ring-opening chemistry of various cyclic carbonates resulting in valuable carbamate products.

\section{Carbamates via Ring-Opening Chemistry}

Since the first preparation of ethyl carbamate in 1845 by Wohler, ${ }^{[13]}$ carbamates have become highly interesting synthetic targets due to their wide application as important starting materials of polyurethanes, agrochemicals and pharmaceuticals. ${ }^{[14]}$ Traditionally carbamates are prepared from phosgene, carbamoyl chloride or isocyanates, which has been well documented. ${ }^{[15]}$

Ring opening of cyclic carbonates by amines represents a straightforward and ecofriendly method toward carbamate formation. The aminolysis of cyclic carbonates with alkyl amines to deliver alkyl carbamates/urethanes typically occurs at room temperature without the need for a catalyst, ${ }^{[16]}$ while these reactions generally proceed with poor regio-selectivity giving rise to a mixture of two regioisomers (Scheme 1, path a). In sharp contrast, the use of poorly nucleophilic aryl amines toward the formation of $\mathrm{N}$-aryl carbamate products is quite challenging. Selva et al. reported that, in the presence of an ionic liquid catalyst, the reaction between propylene carbonate and aniline requires very high temperature $\left(>140{ }^{\circ} \mathrm{C}\right)$ resulting in a complex reaction mixture and, importantly, without any linear carbamate product noted (Scheme 1, path b). ${ }^{[17]}$

The Kleij group recently reported the formation of $\mathrm{N}$-aryl carbamates from aryl amines and cyclic carbonates under ambient conditions in the presence of 1,5,7triazabicyclo[4.4.0]dec-5-ene (TBD) as organocatalyst, and most of the reactions could be performed under solvent-free conditions (Scheme 2, path a). ${ }^{[18]}$ The $\mathrm{N}$-aryl carbamate products are potentially useful precursors for $\mathrm{N}$-aryl isocyanates, which are used on a large scale in the production of polyurethanes. ${ }^{[14 a]}$ DFT calculations revealed a proton-relay mechanism based on a hydrogen bonding activation by TBD (Scheme 2, below). ${ }^{[18]}$ Interestingly, this proton-relay system proved to be feasible for the regioselective aminolysis of di- or trisubstituted cyclic carbonates with alkyl amines (Scheme 2, path b). ${ }^{[19]}$ Control experiments suggested that the use of TBD catalyst is crucial for achieving high regioselectivity. The steric demand in the cyclic carbonate substrate was proposed to be the key factor for selective $\mathrm{C}-\mathrm{O}$ bond scission.
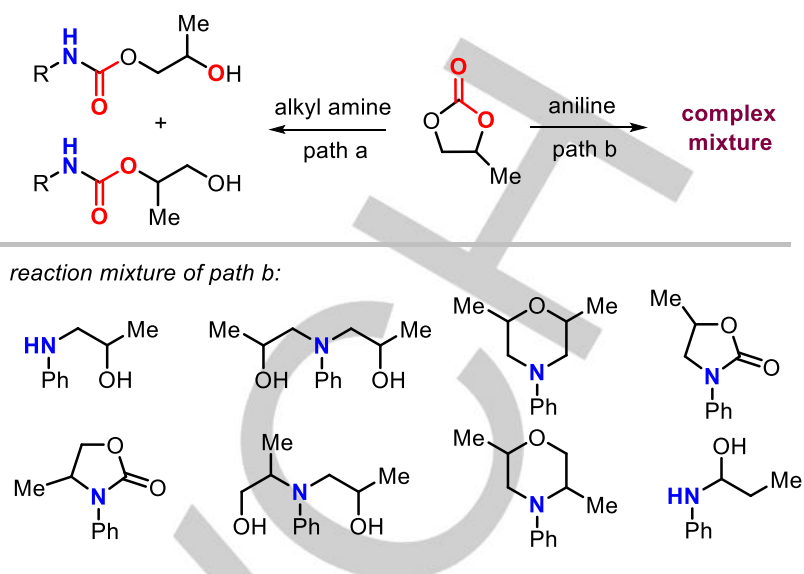

Scheme 1. Aminolysis of cyclic carbonates by alkyl amines (path a) and formation of a complex reaction mixture (below) using aniline and propylene carbonate as reagents (path b).

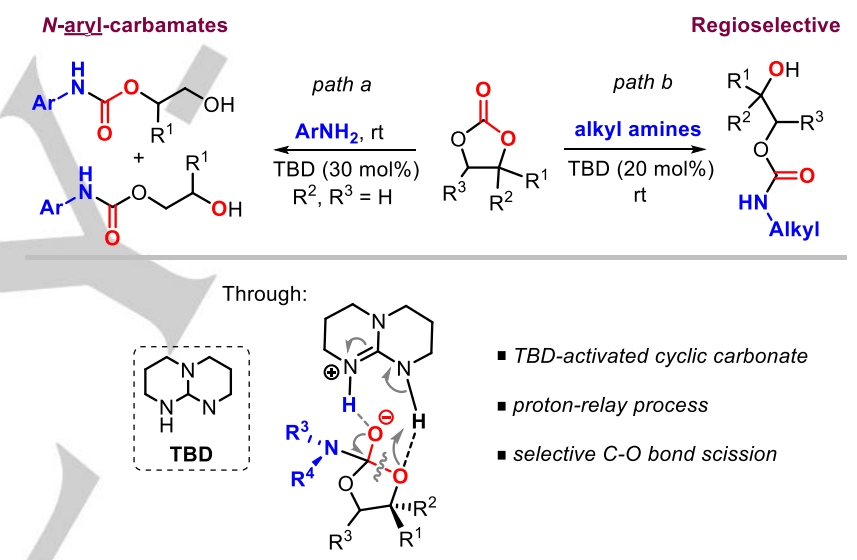

Scheme 2. TBD-catalyzed regioselective aminolysis of cyclic carbonates (path a), and formation of $\mathrm{N}$-aryl carbamates (path b) under ambient conditions.

Following a similar aminolysis procedure, one-pot catalytic procedures have also been developed allowing the synthesis of carbamates using in situ prepared cyclic or polycarbonate reagents. Simple variation of the reaction conditions favourable for epoxide/ $\mathrm{CO}_{2}$ coupling gave rise to either oligomeric carbonate or cyclic carbonate intermediates. Subsequent in situ aminolysis of these intermediates resulted in the selective formation of either trans- or cis-configured hydroxy carbamates (Scheme 3). ${ }^{[20 a]}$ The stereodivergent synthesis leading to these carbamates was supported by various control experiments, and conceptually this approach offers a new tool for the stereodivergent synthesis of $\mathrm{CO}_{2}$-derived fine chemicals albeit with moderately high yields and sometimes relatively long reaction times (66 h) were required. At a later stage, aminolysis of in situ prepared six-membered carbonates obtained from oxetanes and $\mathrm{CO}_{2}$ demonstrated that this chemistry is of use for the preparation of drug-relevant molecules such as the muscle relaxant Carisoprodol.[20b] The Lu laboratory reported a similar concept for chiral carbamate synthesis from meso-epoxides using an enantiopure dinuclear Co(III) catalyst. ${ }^{[21]}$ 


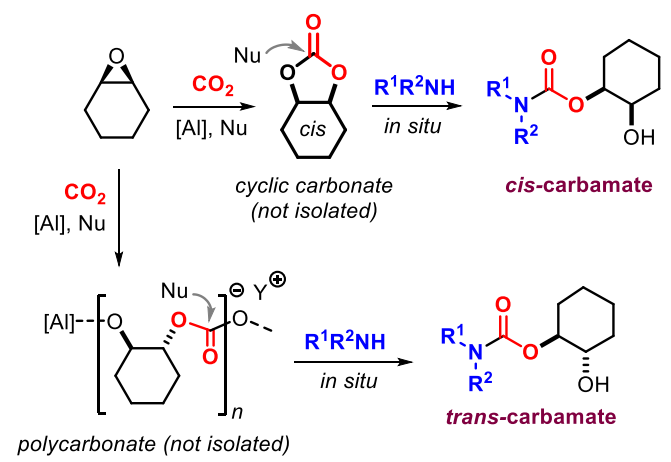

Scheme 3. Exemplary selective formation of cis- and trans-configured carbamates by trapping of in situ formed oligocarbonates or cyclic carbonates with amines. [Al] stands for an $\mathrm{Al}(\mathrm{III})$ aminotriphenolate complex, $\mathrm{Nu}$ is nucleophile, $\mathrm{Y}$ is typically $\mathrm{NBu}_{4}$.

Cyclic carbonates also can be used as effective acylation reagents for amines toward the preparation of five-membered cyclic carbamates, also known as oxazolidinones. ${ }^{[22]}$ Ionic liquids (ILs) are the most frequently used catalysts for these transformations. For example, the Gao group reported that 1butyl-3-methyl-imidazolium acetate (BmimOAc) acts as an efficient catalyst for the acylation of anilines using ethylene carbonate. ${ }^{[22 a]}$ Mass analysis suggested a cooperative activation mode based on hydrogen bonding interaction between the ILs and the reaction partners (Scheme 4).

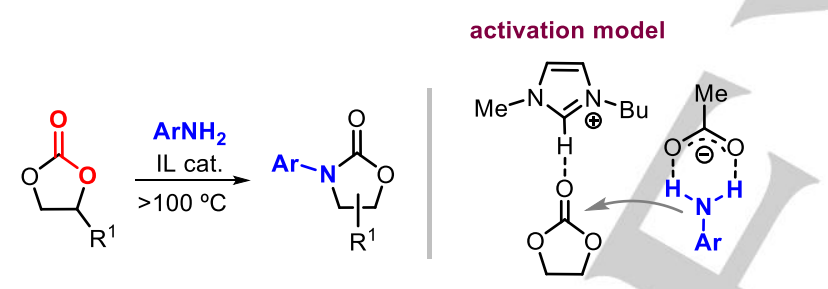

Scheme 4. Acylation of amines with cyclic carbonates, and the proposed mode of activation by the ionic liquid.

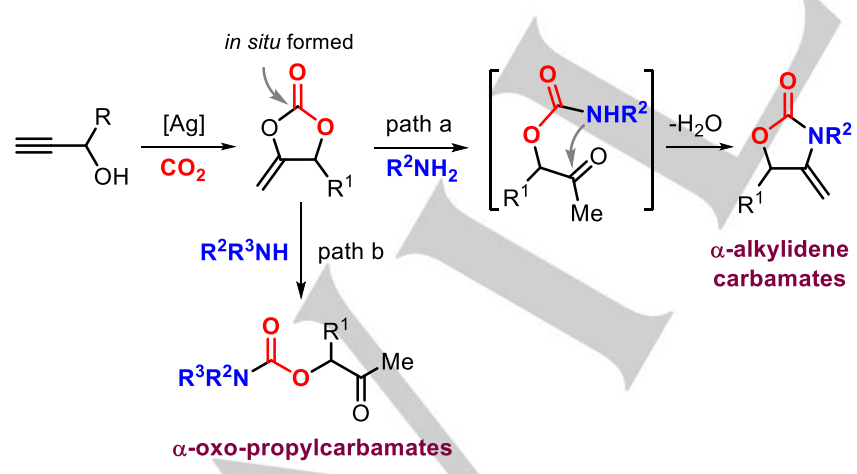

Scheme 5. Carbamate synthesis from $\alpha$-alkylidene cyclic carbonates.

$\mathrm{He}$ and co-workers described a Ag-catalyzed one-pot threecomponent strategy for carbamate synthesis starting from propargylic alcohols, amines and $\mathrm{CO}_{2}{ }^{[23]}$ In the presence of primary amines, the aminolysis of alkylidene-based cyclic carbonate intermediate was followed by dehydration resulting in cyclic carbamate products (Scheme 5, path a). ${ }^{[23 a]}$ With the introduction of secondary amine nucleophiles, the process gave selectively rise to linear, $\alpha$-oxo-propylcarbamates (Scheme 5 , path b). ${ }^{[23 b]}$ Thus, by a judicious choice of the amine nucleophile the chemo-selectivity towards either cyclic or linear carbamates could be controlled. In the next section, transition metal mediated regio-, stereo- and enantioselective transformations of functionalized cyclic carbonates will be discussed.

\section{Transition Metal-Catalyzed Decarboxylative Transformations of Cyclic Carbonates}

Decarboxylative transformations of cyclic carbonates date back to 1963, when Braun reported the lithium chloride catalyzed pyrolysis of divinylethylene carbonate producing the corresponding epoxide. ${ }^{[24]}$ Seminal work from the Yoshida group illustrated that $\mathrm{Pd}$-catalyzed decarboxylative carbonylation of cyclic carbonates toward the formation of vinyl lactones can be readily achieved, and this represents the first transition metal catalyzed decarboxylative transformations of VCCs (Scheme 6). ${ }^{[25]}$ In the last decade, the synthetic potential of these vinyl cyclic carbonates (VCCs) has been tremendously boosted through the development of a wide variety of decarboxylative functionalization processes. In sharp contrast, the catalytic transformations of alkynyl cyclic carbonates have been much less investigated and some notable examples will be discussed briefly.

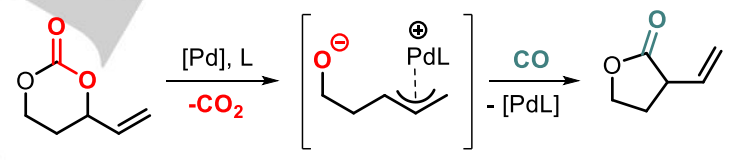

Scheme 6. Pd-catalyzed decarboxylative carbonylation of a VCC.

\subsection{Reactions of VCCs with Nucleophiles}

The transition metal catalyzed conversions of VCCs in the presence of nucleophiles were reported in the 1990s. ${ }^{[26]}$ The reactivity of VCCs and the related vinyl epoxides proved to be quite different. ${ }^{[26 a, b]}$ Moreover, substituted VCCs are much more accessible and modular synthesis of these carbonate precursors is generally facile using $\beta$-hydroxyketones as a starting point. The $\mathrm{Pd}$ - and Cu-catalyzed decarboxylative coupling of external nucleophiles and VCCs was examined by Kleij et al. who reported the stereoselective synthesis of a range of allylic compounds through $\mathrm{C}-\mathrm{N}, \mathrm{C}-\mathrm{O}, \mathrm{C}-\mathrm{S}, \mathrm{C}-\mathrm{C}$ and $\mathrm{C}-\mathrm{B}$ bond formation reactions. ${ }^{[27]}$ As shown in Scheme 7 , in the presence of a suitable palladium/copper precursor and ligand, the formation of a sixmembered palladacyclic or Cu-Bpin(VCC) intermediate sets up the subsequent nucleophilic attack to afford the substituted (Z)- or $(E)$-configured allylic derivatives. In the case of aryl amine nucleophiles, extensive DFT calculations suggested that the pathway leading to the $(E)$-configured allylic amines proceeds through an epoxide intermediate requiring significantly higher energy for the $\mathrm{CO}_{2}$ extrusion step, and thus is disfavoured under ambient conditions. ${ }^{[27 a]}$ This approach based on the use of VCC substrates as allylic surrogates offers a general entry for the synthesis of otherwise challenging tri/tetra substituted (Z)-allylic 
scaffolds. The use of aliphatic amines in this system, however, predominantly gave carbamate products as discussed in section 2. [27e]

The use of water as a nucleophile also proved to be feasible leading to (Z)-1,4-but-2-ene diol formation. ${ }^{[27 b]}$ The application of more challenging thiol nucleophiles required higher reaction temperatures resulting in stereoselective allylic thioether formation. ${ }^{[27 c]}$ Under suitable oxidative conditions, one-pot synthesis of pharmaceutically relevant sulfones was achieved. ${ }^{[27 c]}$ Shortly hereafter, Fernández and co-workers reported a selective $\mathrm{S}_{\mathrm{N}} 2$ ' borylation of VCCs under copper catalysis. ${ }^{[27 d]}$ With the introduction of a substituent on the terminal position of the vinyl group, asymmetric decarboxylative alkylation of VCCs with azlactone nucleophiles could be achieved; preliminary mechanistic studies suggested that hydrogen bonding between the in situ formed Pd-allyl complex and the azlactone substrate is crucial to control the regioselectivity in this $\mathrm{C}-\mathrm{C}$ bond formation process. ${ }^{[28]}$
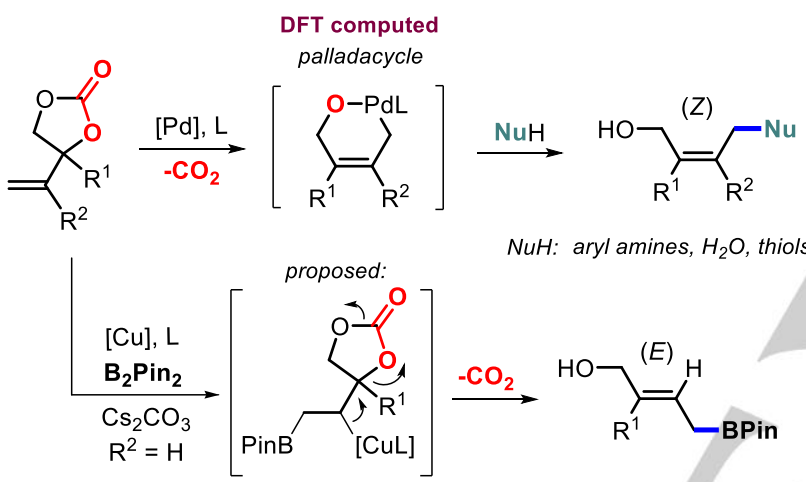

Scheme 7. $\mathrm{Pd}$ - and Cu-catalyzed decarboxylative formation of highly substituted (Z)- or (E)-configured allylic scaffolds from VCCs.

By judicious choice of the ligand and palladium precursor, a dynamic kinetic asymmetric transformation of VCCs would be feasible if the $\pi-\sigma-\pi$ interconversion occurs faster than subsequent nucleophilic attack (Scheme 8). ${ }^{[29]} \mathrm{Kleij}$ and coworkers recently developed the first general method toward the synthesis of otherwise challenging sterically demanding chiral $\alpha, \alpha$-disubstituted allylic aryl amines using VCCs. ${ }^{[29 a]}$ The presence of a phosphoramidite ligand proved to be key toward the induction of high regio- and enantioselectivities. Despite the high asymmetric induction of up to $97 \%$ ee, a detailed mechanistic understanding of the modus operandi of the catalyst and specifically how the catalyst controls the regioselective attack of the amine nucleophile is not yet available.

This catalytic system tolerates various functional groups present in either the VCC or the aryl amine reagent. The corresponding products are essentially chiral vicinal amino alcohols, which are of high synthetic and biological interest. This concept was further extended to the synthesis of allylic aryl ethers using phenol nucleophiles. The presence of $\mathrm{Cs}_{2} \mathrm{CO}_{3}$ was shown to direct the nucleophilic attack of the phenol toward the sterically crowded internal carbon center of the allyl-Pd intermediate due to a strong interaction between oxygen and metal cationic species. Changing the reaction conditions and the ligand gave selectively rise to the corresponding linear (Z)-configured allylic aryl ethers (cf. Scheme 7). ${ }^{[29 b]}$ Related work from the Zhang group illustrated that the asymmetric synthesis of $\alpha$-mono-functionalized allylic amines is also feasible, though the process is limited to the use of potassium phthalimide as reaction partner. ${ }^{[29 c]}$ In contrast, the $\mathrm{Pd}$-catalyzed asymmetric conversion of 1,2-divinylethylene cyclic carbonate in the presence of nucleophiles is more complex. It was proposed that both kinetic resolution and desymmetrization are involved in the overall reaction manifold. ${ }^{[30]}$

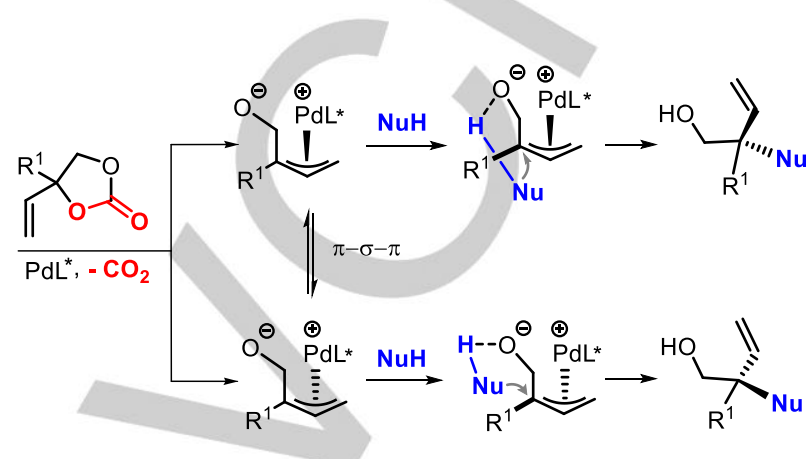

Scheme 8. Pd-catalyzed decarboxylation of VCCs affording chiral branched allylic compounds.

Ir-catalyzed decarboxylative transformations were pioneered by Krische et al. who reported on enantioselective (hydroxylmethyl)allylation of alcohols and aldehydes. ${ }^{[31]}$ The formal carbonyl (hydroxylmethyl)allylations using alcohols involve a transfer hydrogenation step mediated by the Ir-catalyst providing a carbonyl nucleophile. The latter combines with the VCC giving rise to $\mathrm{C}-\mathrm{C}$ bond formation between the $\alpha$-carbon of the alcohol and the internal carbon center of the |r-ally| intermediate affording anti-1,3-diols with high enantiomeric excess of up to $99 \% .^{[31]}$ In contrast to these results, Zhang and co-workers developed a protocol allowing to construct chiral 1,2diols and related ethers by directing the attack of the oxygen nucleophile using an organoboron compound as co-catalyst. The boron species first forms a boronate with the decarboxylated VCC after which it interacts with the alcohol reagent or water to deliver the branched allylic ether or 1,2-diol product. In this way, enantioselective construction of tertiary $\mathrm{C}-\mathrm{O}$ bond could be accomplished (Scheme 8; $\mathrm{NuH}=$ alcohols or $\mathrm{H}_{2} \mathrm{O}$ ). ${ }^{[32]}$

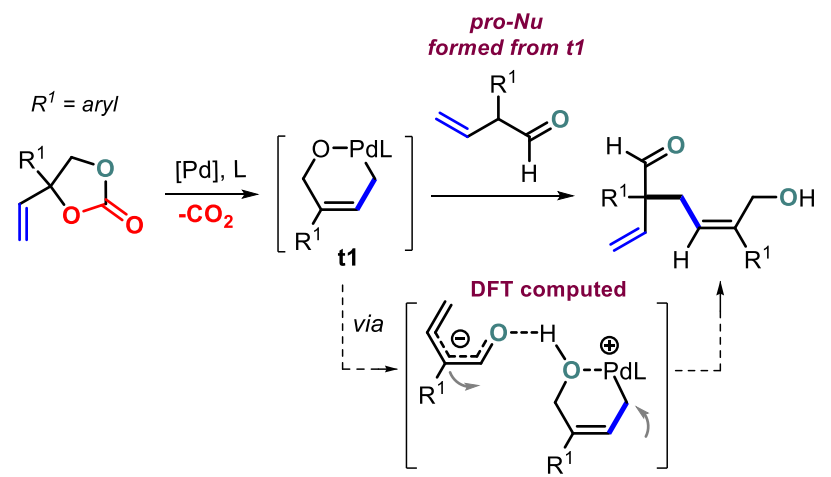

Scheme 9. Pd-catalyzed domino process toward the synthesis of allylic alcohols with highly functionalized quaternary carbon centers. 
Apart from externally added nucleophiles, a recent contribution showed that the VCC itself can produce a nucleophilic species in situ and engage with a second decarboxylated VCC to form unusual cross-coupled products. This formal domino process affords rather complex allylic alcohol scaffolds with highly functionalized quaternary (racemic) carbon centers featuring a rare combination of vinyl, aryl and aldehyde groups (Scheme 9), ${ }^{[33]}$ and developing an asymmetric version of this cross-coupling process should be highly attractive. This redox-neutral, stereocontrolled transformation proceeds typically under ambient conditions and provides remarkably high yields (up to $91 \%$ ) of these polyfunctional compounds using a range of VCCs. DFT calculations and microkinetic analysis suggest that the final product originates from the reaction between a sixmembered palladacycle $\mathbf{t} 1$ and an aldehyde pro-nucleophile derived from $\mathbf{t} 1$ (Scheme 9). Further experiments and calculations revealed that there exists a subtle electronic control in the VCC as to modify the nature of the major product of the reaction. This work may pave the way for cross-coupling reactions based on other similar type of vinyl-substituted heterocycles thereby expanding the pool of synthetic complexity.

\subsection{Reactions of VCCs with Electrophiles}

Decarboxylative cyclization of six-membered VCCs and isocyanate electrophiles was first reported by Tamaru et al. in 1994 to furnish stereoselectively cyclic carbamates. ${ }^{[34]}$ Zhang and co-workers later utilized this concept to develop the asymmetric synthesis of various useful five-membered heterocycles from fivemembered VCCs and different electrophiles as reaction partners (Scheme 10; path a) ${ }^{[35]}$ the same group also reviewed these activities. ${ }^{[36]}$ In order to avoid unnecessary duplication, a detailed discussion of this concept is not included in the present minireview.
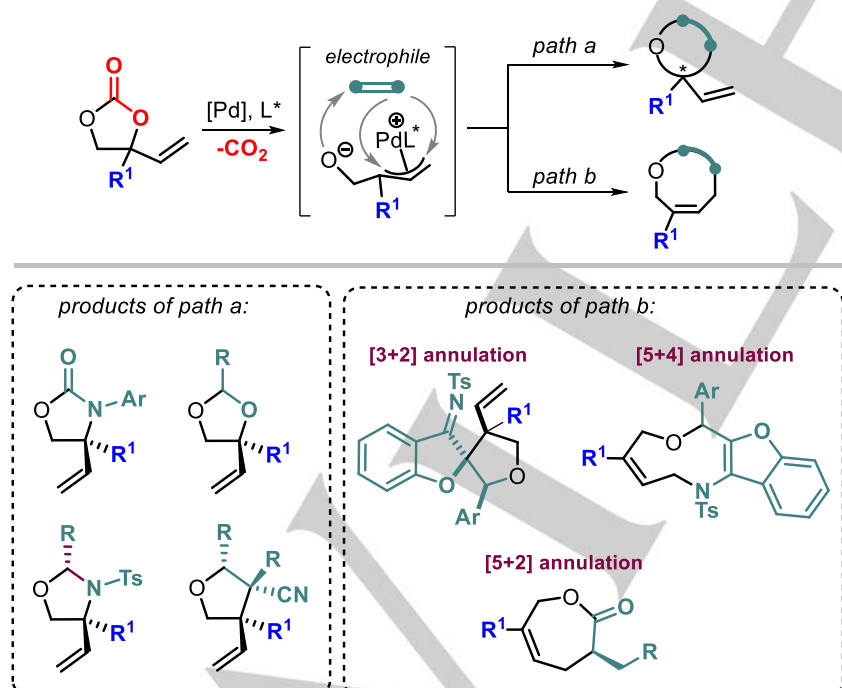

Scheme 10. Pd-catalyzed decarboxylative annulation of VCCs in the presence of various electrophiles.

The Zhao group achieved a decarboxylative formation of ninemembered heterocycles through a Pd-catalyzed [5+4] annulation procedure using $N$-tosyl azadienes as electrophiles (Scheme 10; path b). ${ }^{[37 a]}$ The asymmetric version was also successfully developed with appreciable to high enantioselectivity $(80-92 \%$ ee) and good isolated yields of typically $>80 \%{ }^{[37 b]}$ Interestingly, the product of the annulation process highly depended on the substitution in the VCC substrate ( $\mathrm{R}^{1}$ in Scheme 10). When $\mathrm{R}^{1}$ was an aryl group, [5+4] annulation took place and ninemembered benzofuran-fused heterocycles were selectively formed. The use of nonsubstituted VCCs $\left(R^{1}=H\right)$ afforded fivemembered spiroheterocycles via a diastereoselective formal [3+2] cycloaddition (Scheme 10). ${ }^{[37 a]}$

In addition to these aforementioned annulations, Glorius and co-workers developed the first VCC-based enantioselective [5+2] cycloaddition using a dual catalyst derived from a chiral NHC and a Pd-allyl species derived from the VCC (Scheme 10, path b). ${ }^{[38]}$ The presence of a bidentate phosphine ligand was crucial to prevent binding of the NHC to the active palladium catalyst. The enantioselective synthesis of seven-membered structures and beyond is quite challenging due to unfavorable entropy effects and transannular interactions. Thus, these annulation reactions reported by Zhao ${ }^{[37]}$ and Glorius ${ }^{[38]}$ pave the way for the asymmetric synthesis of challenging larger-ring macrocycles. ${ }^{[39]}$

\subsection{Cyclization through Rearrangement using VCCs}

Yamada and co-workers communicated the stereospecific and regioselective construction of highly substituted (mostly trans) 2-cyclopentenones via Lewis-acid catalyzed decarboxylative Nazarov cyclizations of VCCs (Scheme 11). ${ }^{[40]}$ Control experiments indicated that the geometry of the substituted allyl in the VCC substrate has a pronounced effect on the stereochemistry of the final cyclopentenone product, and its substitution pattern is different from classical Nazarov type cyclizations.

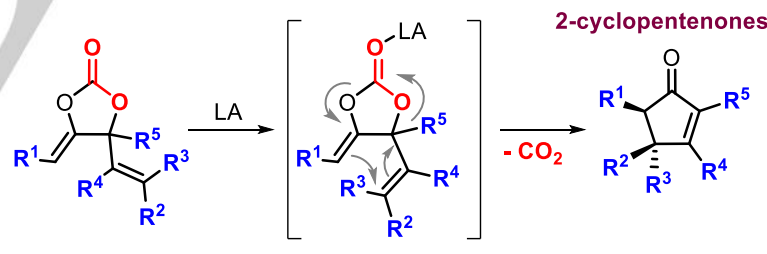

Scheme 11. Lewis acid catalyzed decarboxylative Nazarov cyclization.<smiles>[R]C[C@H]1[C@@H]([CH])[C@@]1(C)CO</smiles>

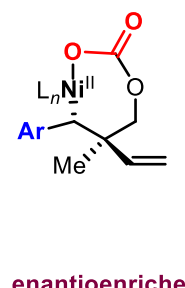
cyclopropanes

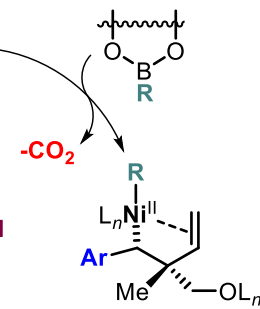
formation of enantioenriched cyclopropanes. 
The Krische group has developed a strategy for the stereospecific synthesis of cyclopropanes under nickel catalysis using enantioenriched six-membered VCCs and boroxines or $\mathrm{B}_{2}(\text { pin) })_{2}$ as starting materials (Scheme 12). ${ }^{[41]}$ The reaction is proposed to start from the stereospecific oxidative addition of $\mathrm{Ni}(\mathrm{COD})_{2}$ to the benzylic $\mathrm{C}-\mathrm{O}$ bond of the VCC with inversion of configuration to furnish a $\sigma$-benzylnickel(II) complex. This $\mathrm{Ni}(\mathrm{II})$ complex undergoes a decarboxylation and transmetalation sequence in the presence of the boron reagent. The resultant $\mathrm{Ni}(\mathrm{II})$-alkene complex is in equilibrium through reversible migratory insertion providing a (cyclopropylcarbinyl)nickel(II) intermediate. Reductive elimination from the latter, presumed to be a single diastereoisomer, releases the cyclopropane target and regenerates the catalyst. Despite the intrinsic reactivity of the $\mathrm{Ni}$-catalyst, the process tolerates a variety of heterocyclic functionalities. A better understanding of the origin of the diastereoselectivity would, however, be desired.

\subsection{Allylation through $\mathrm{C}-\mathrm{H}$ Activation with VCCs}

C-H functionalization has become an important strategy toward the build-up of more complex architectures, ${ }^{[42]}$ and often a directing group is installed in the starting material. Wang and coworkers reported in 2014 a $\mathrm{Rh}$-catalyzed $\mathrm{C}-\mathrm{H}$ allylation of benzamides using VCCs. In this protocol, the alkene group of the VCC inserts into an initially formed aryl-Rh complex. After this insertion step decarboxylation occurs and stabilization of the resultant $\mathrm{Rh}$ complex is facilitated through a bidentate coordination of the inserted homoallyl-oxo fragment via $\mathrm{Rh}$ (alkene) and $\mathrm{Rh}(\mathrm{O})$ coordination. Base-induced elimination of the $(E)$-configured allylated arene regenerates the $\mathrm{Rh}$ catalyst. Apart from aromatic $\mathrm{C}-\mathrm{H}$ activation, olefinic $\mathrm{C}-\mathrm{H}$ activation was also feasible with this catalyst system (Scheme 13; product 1). ${ }^{[43]}$

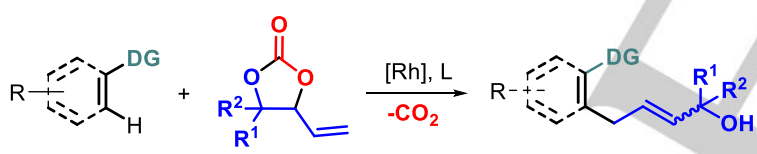

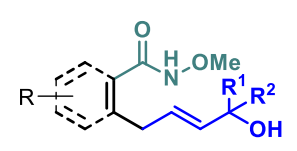

$$
\begin{aligned}
& \text { 1: E/Z typically }>20: 1 \\
& \text { for } R^{1}=R^{2}=H \\
& \text { ref. } 43
\end{aligned}
$$

indoline C7-allylation<smiles>[R]c1cccc(C/C=C\CO)c1N(CC)C(=O)NCCCCC</smiles>
ref. $44 \mathrm{~b}$

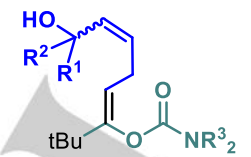

2: $(Z, Z) /(Z, E)$ up to $8: 1$ for $R^{1}=R^{2}=H ; R^{3}=M e$ ref. $44 a$

$$
\text { indole C2-allylation }
$$

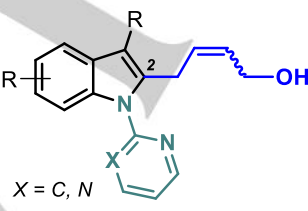

4: $E / Z>20: 1$ refs. $44 \mathrm{~b}, 45$

Scheme 13. Transition metal catalyzed decarboxylative allylation through $\mathrm{C}-\mathrm{H}$ functionalization.

This type of chemistry was further developed by other groups using different types of directing groups (DGs) towards the

synthesis of various allylic alcohol scaffolds (Scheme 13; products 2-4). ${ }^{[4]}$ Recent focus has shifted toward the use of more sustainable, earth-abundant transition metal catalysts based on cobalt and manganese. Seminal contributions from both Ackermann and Glorius focused on the $\mathrm{Mn}(\mathrm{I})$-catalyzed $\mathrm{C}-\mathrm{H}$ allylation of indoles using either a pyridyl or $\mathrm{N}$-pyrimidyl as directing group (Scheme 13; product 4). ${ }^{[45]}$ The products were typically isolated with moderately high $E / Z$ ratios of around 80:20. Notably, the $\mathrm{Yu}$ group demonstrated that the Co-catalyzed $\mathrm{C}-\mathrm{H}$ allylation of indoles can also be achieved under solvent-free conditions using mechanochemical activation. The high-speed ball-milling process could remarkably shorten the reaction time to only 30 min without external heating. ${ }^{[46]}$
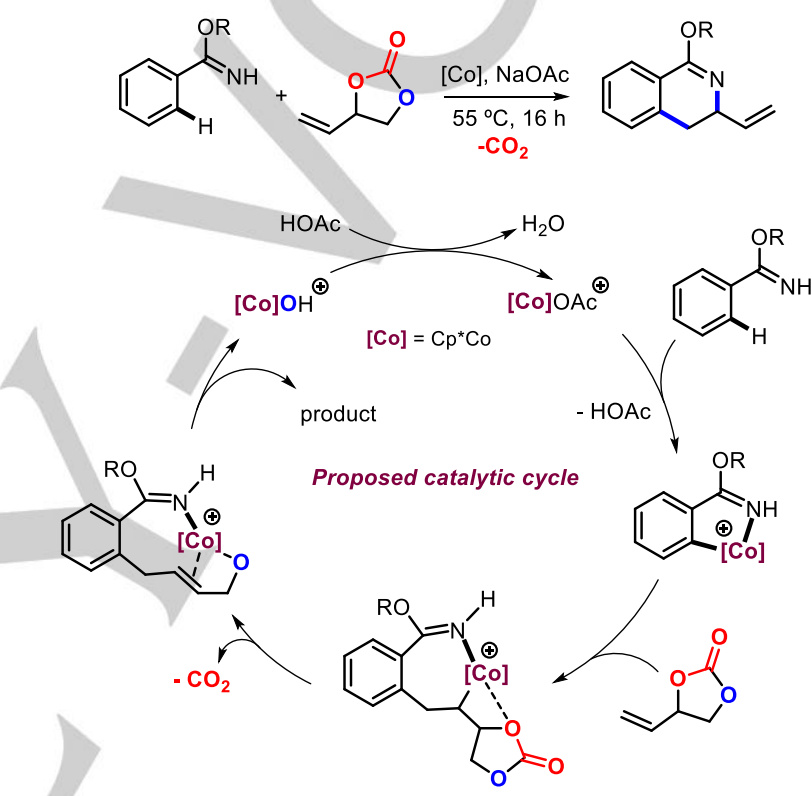

Scheme 14. Co-catalyzed decarboxylative domino allylations of imidates

More recently, the Ackermann group reported a domino $\mathrm{C}-\mathrm{H} / \mathrm{N}-\mathrm{H}$ allylation of aryl imidates by a versatile cobalt(III) catalyst (Scheme 14). ${ }^{[4]}$ This process features the formation of substituted dihydroisoquinolines with only $\mathrm{CO}_{2}$ and $\mathrm{H}_{2} \mathrm{O}$ as byproducts. The imidate directing group is integrated into the final product and as such, there is no need for its removal postsynthetically adding further to the atom efficiency of this Cocatalyzed transformation. This system tolerates the presence of a relatively wide series of functional groups in the imidate substrate including ester and amide substituents. Mechanistic investigations (kinetic isotope effects and competition experiments) suggest that the reaction starts with a ratedetermining $\mathrm{C}-\mathrm{H}$ activation step with the formation of a cationic Co(III) complex.

\subsection{Transformations of Cyclic Alkenyl Carbonates}

In addition to VCCs, alkylidene carbonates have also shown to be useful as synthetic precursors. The oxidative addition of low valent palladium to cyclic alkenyl carbonates results in effective decarboxylation and generates an oxo-allyl-Pd intermediate 
(Scheme 15). ${ }^{[48]}$ The zwitterionic $\eta^{3}$-allyl-Pd species is believed to be in dynamic equilibrium with a $\eta^{2}$-palladacyclobutanone and incorporates both nucleophilic and electrophilic character (Scheme 15). A range of electrophiles and reagents could trap this reactive palladium intermediate resulting in the formation of useful compounds such as functionalized norbornenes, oxazolidinones, highly functionalized 2,5-dihydrofurans and silyl enol ethers. ${ }^{[48 a]}$ Further application of this concept was established by Hayashi et al. who used six-membered 2alkylidene-trimethylene carbonates as starting materials to furnish cyclopropanated oxazolidinone products. ${ }^{[48 \mathrm{~b}]}$

Cyclic alkenyl carbonates, being synthetic equivalents to enolates upon decarboxylation, were also applied by Kakiuchi and co-workers in the $\mathrm{Rh}$-catalyzed $\mathrm{C}-\mathrm{H}$ functionalization of arenes in the formation of $\alpha$-aryl ketones. In situ treatment of the reaction mixture with acetic acid resulted in the generation of valuable isocoumarins (Scheme 16). ${ }^{[49]}$ The $\mathrm{C}-\mathrm{C}$ bond formation was proposed to take place through migratory insertion.
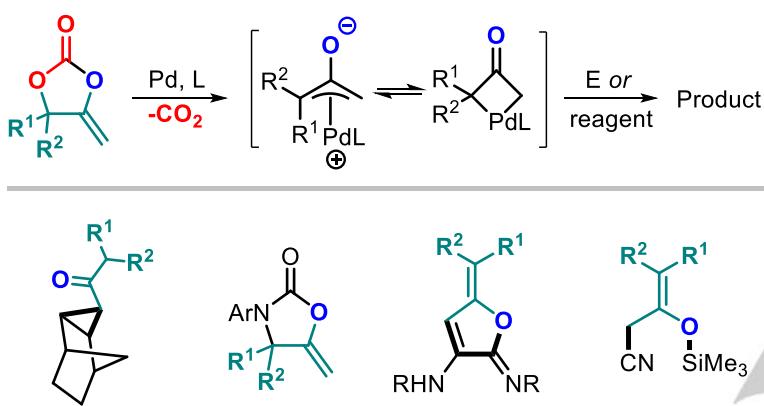<smiles></smiles><smiles></smiles>

Scheme 15. Pd-catalyzed decarboxylative transformations of alkylidene carbonates. E stands for electrophile.

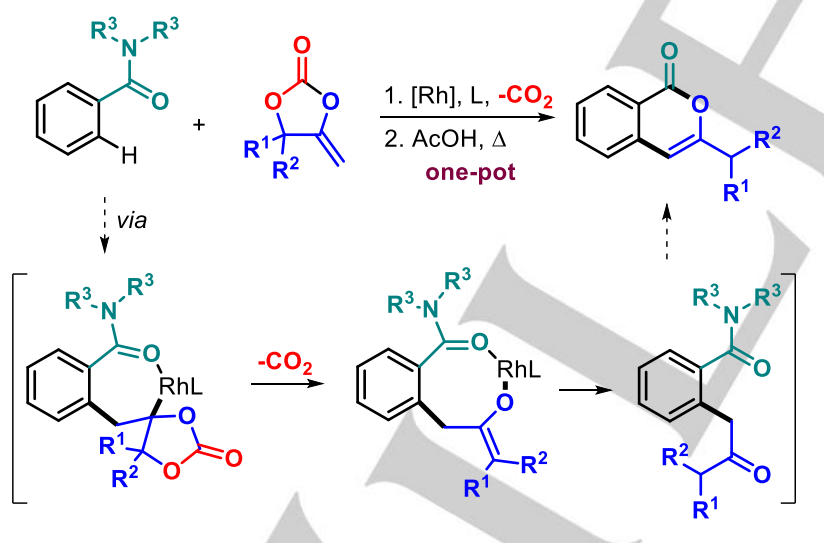

Scheme 16. C-H functionalization of arenes to afford isocoumarins.

Kimura and co-workers recently reported $\mathrm{Ni}$-catalyzed coupling reactions between cyclic alkenyl carbonates and internal alkynes. The main difference compared to the decarboxylative conversion of VCCs is that all atoms of the carbonate substrate are retained in the final product (Scheme 17), i.e. this is not a decarboxylative transformation. The presence of $\mathrm{Me}_{2} \mathrm{Al}(\mathrm{OMe})$ is crucial toward the selective formation of $\beta$-keto-carboxylic acids, and other organometallic reagents such as $\mathrm{Me}_{3} \mathrm{~B}$ and $\mathrm{Me}_{2} \mathrm{Zn}$ proved to be less efficient. An eight-membered nickelacycle was proposed to be the key intermediate in this process. ${ }^{[50]}$

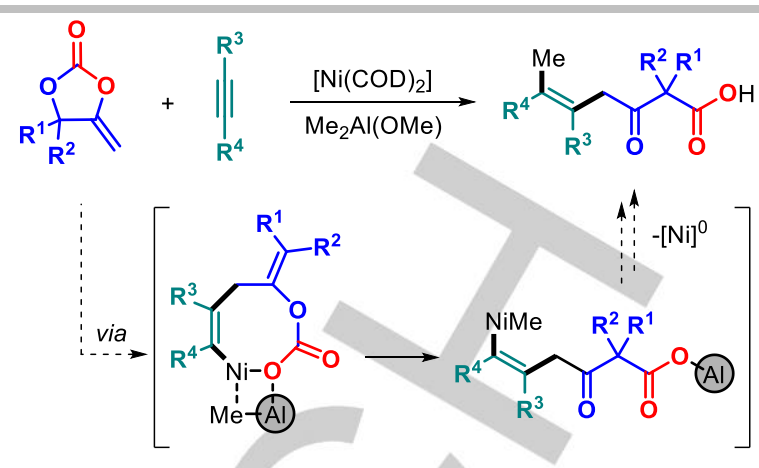

Scheme 17. Ni-catalyzed coupling of cyclic alkenyl carbonates and alkynes with full atom incorporation into the final $\beta$-keto-carboxylic acids.

\subsection{Conversion of Alkynyl Substituted Cyclic Carbonates}

Opposed to VCCs, literature on transition metal mediated conversion of their alkynyl congeners is much more limited despite the synthetic attractiveness of these synthons. The reactivity of alkynyl cyclic carbonates was first explored in 1994 when Dixneuf and co-workers developed a Pd-catalyzed formation of alkynyl $\alpha$-allenols from alkynyl cyclic carbonates and terminal alkynes. ${ }^{[51]}$ Following a similar strategy, the use of these substrates was further explored by the same group in the one-pot formation of 2,5-dihydrofurans in the presence of terminal alkenes as reaction partners (Scheme 18). ${ }^{[52]}$ It was proposed that the reaction starts with a decarboxylation step followed by a Heck coupling and intramolecular nucleophilic addition (cyclization) resulting in the corresponding dihydrofuran products. Krause and co-workers later reported an efficient methodology toward the synthesis of $\alpha$-hydroxyallenes based on Cu-catalyzed transformations of alkynyl cyclic carbonates proving the synthetic potential of alkynyl cyclic carbonates. ${ }^{[53]}$

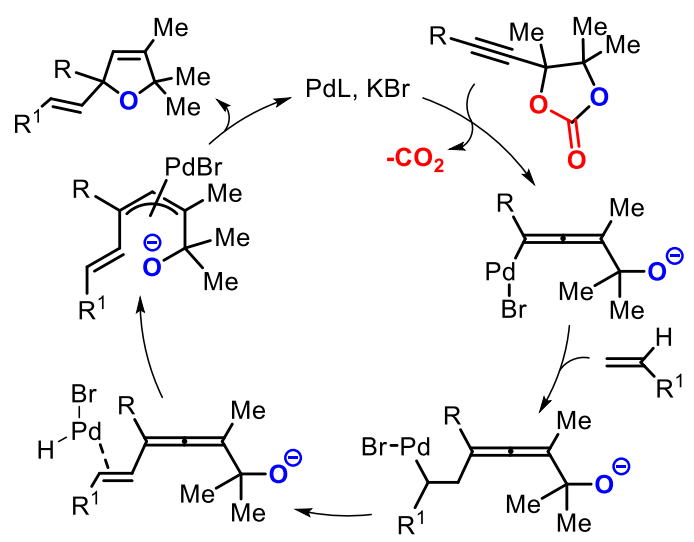

Scheme 18. Pd-catalyzed decarboxylative coupling between alkynyl carbonates and terminal alkenes to give substituted 2,5-dihydrofurans.

More recently, Zhang et al. reported on Cu-mediated decarboxylative transformations of alkynyl carbonates into chiral $\beta$-aminoalcohols in the presence of amine nucleophiles. ${ }^{[54 a]}$ Likely the reaction manifold proceeds through a similar and well-known Cu-allenylidene intermediate as in the case of alkynyl epoxides. ${ }^{[54 b]}$ Alkynyl cyclic carbonates were also reported as substrates in non-decarboxylative cooperative Brønsted 
acid/Mn(I) catalyzed hydroarylations under continuous flow conditions affording $(E)$-configured functionalized allylic cyclic carbonates that are useful for late-stage diversification. ${ }^{[55]}$

\section{Miscellaneous Heterocyclic Substrates}

\subsection{Transformations of 1,4,2-Dioxazol-5-ones}

1,4,2-Dioxazol-5-ones, also known as dioxazolones or cyclic nitrile carbonates, are relatively easy to activate under mild conditions due to a weak $\mathrm{N}-\mathrm{O}$ bond present in the heterocycle. Since the pioneering work reported by Sauer and Mayer in 1968, ${ }^{[56]}$ decarboxylative transformations based on these heterocycles have gained much interest. These substrates have been found especially suitable in reactions that involve $\mathrm{C}-\mathrm{H}$ amidation of (hetero)arenes under transition metal catalysis (Scheme 19). ${ }^{[57-59]}$ The nature of the ligand is crucial for achieving efficient turnover. For instance, the use of strong $\sigma$-donor ligands such as pentamethylcyclopentadienyl $\left(\mathrm{Cp}^{*}\right)$ or $p$-cymene ( $p$-cym), enabled the effective functionalization of the ortho $\mathrm{C}-\mathrm{H}$ bond of the starting arenes. The amidation process was proposed to proceed through a highly reactive $\mathrm{M}^{\mathrm{V}}$-imido species followed by reductive elimination (Scheme 19). ${ }^{[57 a]}$ In this regard, different metal catalysts ( $\mathrm{Co}, \mathrm{Ir}, \mathrm{Rh}, \mathrm{Ru}$ and $\mathrm{Cu}$ ) have been scrutinized for the $\mathrm{C}-\mathrm{H}$ amidation of a variety of (hetero)arenes with pre-installed directing groups. ${ }^{[58,59]}$

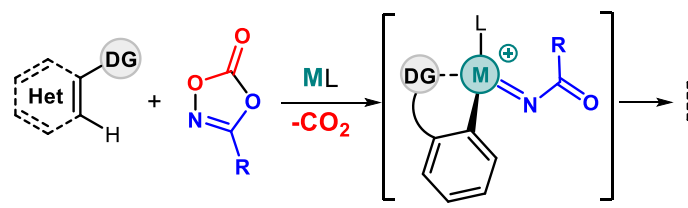<smiles>[R]C(=O)Nc1ccccc1OC</smiles>

Scheme 19. Transition metal catalyzed C-H amidation of (hetero)arenes

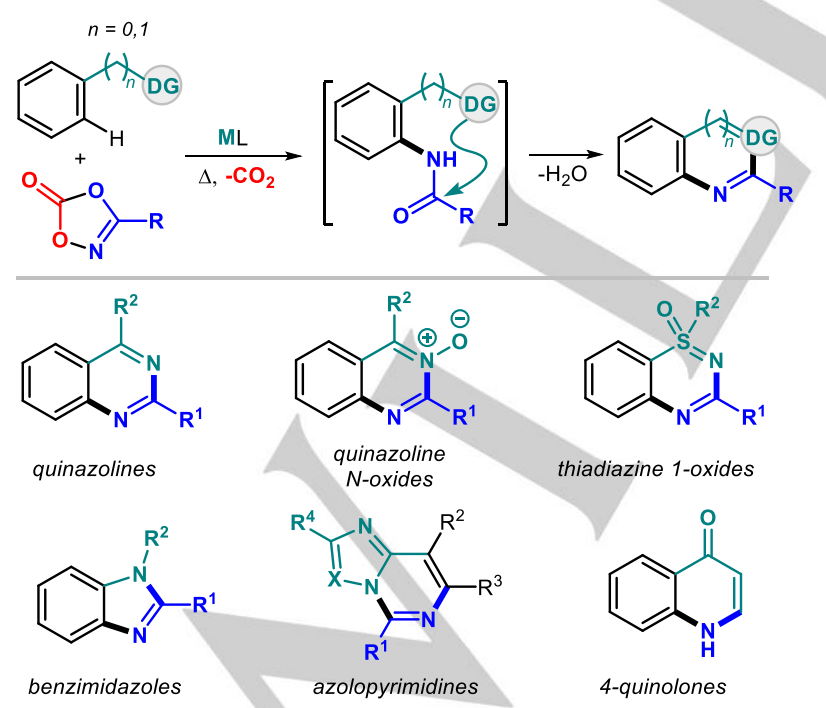

Scheme 20. C-H amidation toward the synthesis of bicyclic compounds.

With the introduction of a directing group possessing nucleophilic or electrophilic character, subsequent intramolecular cyclization after initial $\mathrm{C}-\mathrm{H}$ amidation is feasible giving rise to bicyclic compounds (Scheme 20). Thus, the synthesis of quinazolines $^{[60]}$ and their $\mathrm{N}$-oxides ${ }^{[61]}$, benzimidazoles ${ }^{[62]}$, azolopyrimidines $^{[63]}$ and thiadiazine-1-oxides ${ }^{[64]}$ was achieved in a single step. The use of an electrophilic enaminone directing group gave rise to 4-quinolone product. ${ }^{[65]}$ The amidation of more challenging $\mathrm{C}\left(\mathrm{sp}^{2}\right)-\mathrm{H}$ and $\mathrm{C}\left(\mathrm{sp}^{3}\right)-\mathrm{H}$ bonds can be also achieved though the scope is limited to the use of specially designed substrates such as oxime ethers, substituted 8-methylquinolines and thioamides. ${ }^{[66]}$

In the presence of a Ru(TPP)CO (TPP = tetraphenylporphyrin) catalyst, dioxazolones proved to be suitable substrates for nitrene transfer reactions (Scheme 21). The active catalytic species is generated by dissociation of $\mathrm{CO}$ from the $\mathrm{Ru}$ pre-catalyst, a step which can be promoted by light or thermal energy. After decarboxylation, the $\mathrm{N}$-acyl based $\mathrm{Ru}$ intermediate is capable of transferring the nitrene unit to thioethers and sulfoxides, ${ }^{[67]}$ olefins and alkynes. ${ }^{[68]}$ In the latter case, the addition of $\mathrm{CuCl}_{2}$ is required as a co-catalyst allowing the formation of 2oxazolines and oxazoles.

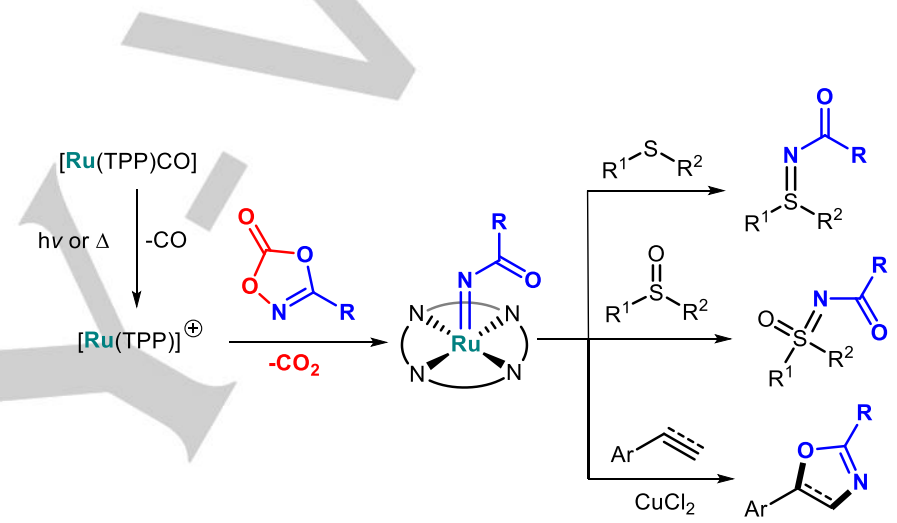

Scheme 21. Ru-catalyzed nitrene transfer reactions using 1,4,2-dioxazol-5ones.

\subsection{Cyclic Carbamate based Heterocycles}

As analogues of cyclic carbonates, cyclic carbamates not only play a pivotal role in drug discovery, agro- and medicinal chemistry, ${ }^{[69]}$ but they have also emerged as powerful building blocks for the preparation of functionalized nitrogen-containing heterocycles through transition-metal catalyzed decarboxylative transformations. ${ }^{[70]}$ In this regard, Lu and co-workers recently reviewed in detail the transition metal catalyzed decarboxylative transformation of vinyl and ethynyl benzoxazinones. ${ }^{[71]}$ Supplementary examples presented in Harrity's review ${ }^{[72]}$ further showcase the great synthetic application potential of these heterocycles.

Based on the prior achievements made in this area, ${ }^{[71,72]}$ new opportunities upon using cyclic carbamates as substrates have been discovered. For example, Glorius and co-workers discovered a regioselective aromatizing cascade strategy to introduce the (2-indolyl)-methyl motif onto heteroarenes through $\mathrm{Mn}(\mathrm{I})$-catalyzed $\mathrm{C}-\mathrm{H}$ activation employing ethynyl benzoxazinones (Scheme 22). ${ }^{[73]}$ The key to the success of this transformation is the use of a heteroaromatic substrate incorporating a 2-pyridyl chelating group. This substrate is able to promote the formation of a crucial organomanganese complex activating the desired $\mathrm{C}\left(\mathrm{sp}^{2}\right)-\mathrm{H}$ bond rather than forming a $\mathrm{Mn}$ - 
allenylidene complex. The manganacycle further reacts with the benzoxazinones through an aromatizing cascade cyclization releasing the diheteroarylmethane product (Scheme 22). Preliminary mechanistic experiments suggested that the $\mathrm{C}-\mathrm{H}$ bond cleavage is probably not the rate-limiting step, but rather olefin coordination and subsequent insertion. The order of the cyclization and protonation steps remained unclear and may occur as presented in scheme 22 or vice versa.

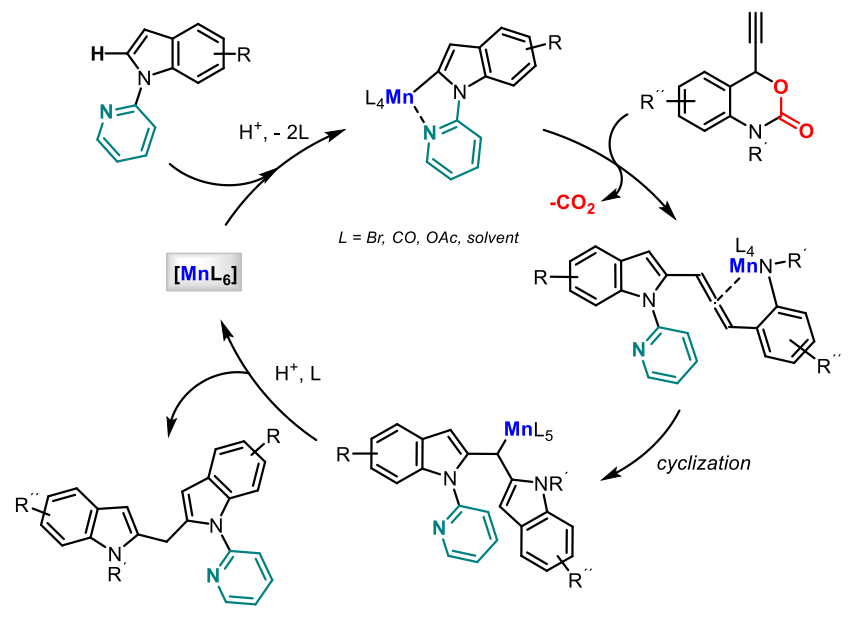

Scheme 22. $\mathrm{Mn}(\mathrm{I})$-catalyzed $\mathrm{C}-\mathrm{H}$ (2-indolyl)methylation using propargylic benzoxazinones.

\section{Conclusion and Outlook}

This minireview undoubtedly demonstrates the synthetic renaissance of heterocycles known as cyclic organic carbonates. In the last decade, a number of new catalytic transformations have displayed exciting new, improved or amplified reactivity and selectivity features. One of the main advantages of these heterocyclic scaffolds is their ease of synthesis and their modular character making them ideally suited for synthetic applications and explorations. Transition metal chemistry concepts can be merged with the use of VCCs and related heterocycles to provide new opportunities such as those described in this minireview. These include $\mathrm{C}-\mathrm{H}$ bond functionalization, stereo- and enantioselective Tsuji-Trost allylic alkylations, and unexplored potential for natural product synthesis.

While most of the synthetic conversions are still based on expensive transition metal catalysts, new potential for VCC valorization requires the development of cheaper catalytic strategies based on abundant metal alternatives. Furthermore, the development of efficient domino processes or cooperative catalytic systems that utilize these VCC substrates would certainly be attractive, ${ }^{[74]}$ though the combination of different catalysts and/or sequential synthetic steps represents a significant challenge. A practical operational window needs to be established for all steps/catalysts matching the requirements of each transformation without affecting the overall catalytic performance. Despite the intrinsic complexity, such multi-step designer preparations can be an attractive future direction for VCC transformations while contemplating a growing importance of decarboxylative functionalization in synthetic chemistry.

\section{Acknowledgements}

We thank the CERCA Program/Generalitat de Catalunya, ICREA, the Spanish MINECO (CTQ2017-88920-P, SEV-2013-0319, and FPI fellowship to J.E.G.) and AGAUR (2017-SGR-232). J.X thanks the CSC (2016-06200061) for a predoctoral fellowship. W.G thanks the starting funding scheme of Xi'an Jiaotong University.

\section{Conflict of Interest}

The authors declare no conflict of interest.

Wusheng Guo earned his PhD degree
in Chemistry in 2014 from the UAB
under the supervision of Prof. Roser
Pleixats and Dr. Alexandr Shafir. Then
he joined ICIQ in Tarragona (Kleij
group) as a postdoc. In 2018, he was
appointed full professor in Frontier
Institute of Science and Technology
(FIST) of Xi'an Jiaotong University
(China). His research interests include hypervalent iodine
chemistry, nanoparticles and transition metal catalysis.

José Enrique Gómez received his BSc and MSc degrees from the University of Valladolid (Spain) under the supervision of Prof. Alfonso PérezEncabo. Since 2015, he has been a $\mathrm{PhD}$ student at ICIQ. He is currently working on transition metal catalyzed stereocontrolled transformations.

Àlex Cristòfol obtained his BSc and MSc (2017) degrees in chemistry from the URV in Tarragona. He is currently pursuing doctoral studies at the ICIQ in the group of Prof. Arjan W. Kleij. His research interests include metal catalysis, and synthesis of biologically active compounds.

Jianing Xie received his MSc degree from Nankai University in 2016 under the supervision of Prof. Liang-Nian He. Currently he is a PhD student in the research group of Prof. Arjan W. Kleij at ICIQ. His current research focus is on stereo/enantioselective transition-metal catalyzed C-N/C-O bond formations.
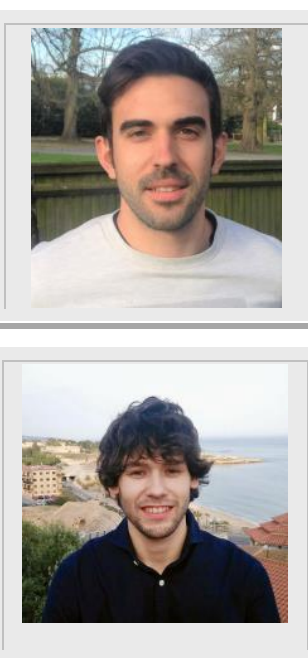

Arjan W. Kleij obtained his $\mathrm{PhD}$ from the University of Utrecht in 2000. After postdoctoral appointments in Madrid (UAM) and Amsterdam (UvA), he started his independent career at ICIQ in 2006, and was promoted to ICREA Professor in 2011. His research interests include small molecule activation and new biopolymer development. 
[1] a) Q. Liu, L. Wu, R. Jackstell, M. Beller, Nat. Commun. 2015, 6, 5933; b) J. Klankermayer, S. Wesselbaum, K. Beydoun, W. Leitner, Angew. Chem. Int Ed. 2016, 55, 7296; c) M. Aresta, A. Dibenedetto, A. Angelini, Chem. Rev. 2014, 114, 1709 .

[2] a) A.-A. G. Shaikh, S. Sivaram, Chem. Rev. 1996, 96, 951; b) C. Martín, G. Fiorani, A. W. Kleij, ACS Catal. 2015, 5, 1353; c) J. W. Comerford, I. D. V. Ingram, M. North, X. Wu, Green Chem. 2015, 17, 1966; d) M. Alves, B. Grignard, R. Mereau, C. Jerome, T. Tassaing, C. Detrembleur, Catal. Sci. Technol. 2017, 7, 2651; e) R. Rajjak Shaikh, S. Pornpraprom, V. D’Elia, ACS Catal. 2018, 8, 419 .

[3] For sustainable approaches see: a) Q.-W. Song, Z.-H. Zhou, L.-N. He, Green Chem. 2017, 19, 3707; b) G. Fiorani, W. Guo, A. W. Kleij, Green Chem. 2015, 17, 1375; c) B. Yu, L.-N. He, ChemSusChem 2015, 8, 52 See also references $2 c-e$.

[4] B. Schäffner, F. Schäffner, S. P. Verevkin, A. Börner, Chem. Rev. 2010, $110,4554$.

[5] a) S. Gennen, B. Grignard, T. Tassaing, C. Jérôme, C. Detrembleur, Angew. Chem. Int. Ed. 2017, 56, 10394; b) S. Schmidt, F. J. Gatti, M. Luitz, B. S Ritter, B. Bruchmann, R. Mülhaupt, Macromolecules 2017, 50, 2296; c) G. L. Gregory, Eva M. López-Vidal, A. Buchard, Chem. Commun. 2017, 53, 2198.

[6] a) J. Muzikar, T. van de Goor, B. Gaš, E. Kenndler, Anal. Chem. 2002, 74, 428; b) H. Zhao, S.-J. Park, F. Shi, Y. Fu, V. Battaglia, P. N. Ross Jr., G. Liu, J. Electrochem. Soc. 2014, 161, A194-A200.

[7] Z. -B. Han, L.-C. Rong, J. Wu, L. Zhang, Z. Wang, K.-L. Ding, Angew. Chem. Int. Ed. 2012, 51, 13041

[8] For selected examples: a) V. Laserna, G. Fiorani, C. J. Whiteoak, E. Martin, E. C. Escudero-Adán, A. W. Kleij, Angew. Chem. Int. Ed. 2014, 53, 10416; b) J. Martínez, J. Fernández-Baeza, L. F. Sánchez-Barba, J. A. CastroOsma, A. Lara-Sánchez, A. Otero, ChemSusChem 2017, 10, 2886; c) C Maeda, J. Shimonishi, R. Miyazaki, J.-Y. Hasegawa, T. Ema, Chem. Eur. J. 2016, 22, 6556; d) H. Büttner, J. Steinbauer, C. Wulf, M. Dindaroglu, H. G. Schmalz, T. Werner, ChemSusChem 2017, 10, 1076.

[9] Recent examples: a) S. Minakata, I. Sasaki, T. Ide, Angew. Chem. Int. Ed. 2010, 49, 1309; b) N. Ishida, Y. Shimamoto, M. Murakami, Angew. Chem. Int. Ed. 2012, 51, 11750; c) B. A. Vara, T. J. Struble, W. Wang, M. C. Dobish J. N. Johnston, J. Am. Chem. Soc. 2015, 137, 7302; d) J. Rintjema, R. Epping, G. Fiorani, E. Martín, E. C. Escudero-Adán, A. W. Kleij, Angew. Chem. Int. Ed. 2016, 55, 3972; e) V. Laserna, E. Martin, E. C. EscuderoAdán, A. W. Kleij, ACS Catal. 2017, 7, 5478.

[10] H. Zhang, H.-B. Liu, J.-M. Yue, Chem. Rev. 2014, 114, 883

[11] B. M. Trost, T. Zhang, J. D. Sieber, Chem. Sci. 2010, 1, 427.

[12] For selected examples: a) Y. Miyake, S. Endo, T. Moriyama, K. Sakata, Y. Nishibayashi, Angew. Chem. Int. Ed. 2013, 52, 1758; b) Q. Wang, T.-R. Li, L.-Q. Lu, M.-M. Li, K. Zhang, W.-J. Xiao, J. Am. Chem. Soc. 2016, 138, 8360.

[13] J. Liebig, E. Wohler, Ann. 1845, 58, 260.

[14] a) H.-W. Engels, H.-G. Pirkl, R. Albers, R. W. Albach, J. Krause, A. Hoffmann, H. Casselmann, J. Dormish, Angew. Chem. Int. Ed. 2013, 52, 9422; b) T. R. Fukuto, Environ. Health Perspect. 1990, 87, 245; c) A. K. Ghosh, M. Brindisi, J. Med. Chem. 2015, 58, 2895.

[15] P. Adams, F. A. Baron, Chem. Rev. 1965 65, 567.

[16] a) M. Blain, L. Jean-Gérard, R. Auvergne, D. Benazet, S. Caillol, B. Andrioletti, Green Chem. 2014, 16, 4286; b) M. Helou, J.-F. Carpentier, S. M. Guillaume, Green Chem. 2011, 13, 266; c) A. Cornille, M. Blain, R Auvergne, B. Andrioletti, B. Boutevin, S. Caillol, Polym. Chem. 2017, 8, 592

[17] M. Selva, M. Fabris, V. Lucchini, A. Perosa, M. Noé, Org. Biomol. Chem. 2010, 8, 5187.

[18] W. Guo, J. Gónzalez-Fabra, N. A. G. Bandeira, C. Bo, A. W. Kleij, Angew. Chem. Int. Ed. 2015, 54, 11686.

[19] S. Sopeña, V. Laserna, W. Guo, E. Martin, E. C. Escudero-Adán, A. W. Kleij, Adv. Synth. Catal. 2016, 358, 2172.

[20] a) W. Guo, V. Laserna, E. Martin, E. C. Escudero-Adán, A. W. Kleij, Chem. Eur. J. 2016, 22, 1722; b) W. Guo, V. Laserna, J. Rintjema, A. W. Kleij, Adv. Synth. Catal. 2016, 358, 1602.

[21] Y. Liu, W.-M. Ren, K.-K. He, W.-Z. Zhang, W.-B. Li, M. Wang, X.-B. Lu, J. Org. Chem. 2016, 81, 8959
[22] a) L. Zhang, X. Fu, G. Gao, ChemCatChem 2011, 3, 1359; b) Y. Song, C. Cheng, H. Jing, Chem. Eur. J. 2014, 20, 12894; c) B. Wang, E. H. Elageed D. Zhang, S. Yang, S. Wu, G. Zhang, G. Gao, ChemCatChem 2014, 6, 278; d) B. Wang, Z. Luo, E. H. Elageed, S. Wu, Y. Zhang, X. Wu, F. Xia, G. Zhang, G. Gao, ChemCatChem 2016, 8, 830; e) Y. Zhang, B. Wang, E. H. Elageed, L. Qin, B. Ni, X. Liu, G. Gao, ACS Macro Lett. 2016, 5, 435; g) R. Gupta, M. Yadav, R. Gaur, G. Arora, R. K. Sharma, Green Chem. 2017,19, 3801 ; h) Q.-W. Song, Z.-H. Zhou, M.-Y. Wang, K. Zhang, P. Liu, J.-Y. Xun, L.-N. He, ChemSusChem 2016, 9, 2054; i) U. R. Seo, Y. K. Chung, Green Chem. 2017, 19, 803

[23] a) Q.-W. Song, B. Yu, X.-D. Li, R. Ma, Z.-F. Diao, R.-G. Li, W. Li, L.-N. He, Green Chem. 2014, 16, 1633; b) Q.-W. Song, W.-Q. Chen, R. Ma, A. Yu, Q.-Y. Li, Y. Chang, L.-N. He, ChemSusChem 2015, 8, 821.

[24] R. A. Braun, J. Org. Chem. 1963, 28, 1383.

[25] Y. Tamaru, T. Bando, M. Hojo, Z. Yoshida, Tetrahedron Lett. 1987, 28, 3497.

[26] a) B. M. Trost, J. R. Granja, Tetrahedron Lett. 1991, 32, 2193; b) R. Mizojiri, Y. Kobayashi, J. Chem. Soc. Perkin Trans. I, 1995, 2073; c) S.-K. Rang, S.-G. Kim, J.-S. Lee, Tetrahedron: Asymmetry 1992, 3, 1139

[27] a) W. Guo, L. Martínez-Rodríguez, R. Kuniyil, E. Martin, E. C. EscuderoAdán, F. Maseras, A. W. Kleij, J. Am. Chem. Soc. 2016, 138, 11970; b) W Guo, L. Martínez-Rodríguez, E. Martin, E. C. Escudero-Adán, A. W. Kleij, Angew. Chem. Int. Ed. 2016, 55, 11037; c) J. E. Gómez, W. Guo, A. W. Kleij, Org. Lett. 2016, 18, 6042; d) N. Miralles, J. E. Gómez, A. W. Kleij, E. Fernández, Org. Lett. 2017, 19, 6096. Note that at a later stage the use of aliphatic amines toward chiral allylic amine synthesis was reported though using a linear carbonate substrate: e) W. Guo, A. Cai, J. Xie, A.W. Kleij, Angew. Chem. Int. Ed. 2017, 56, 11797.

[28] X. Wei, D. Liu, Q. An, W. Zhang, Org. Lett. 2015, 17, 5768

[29] a) A. Cai, W. Guo, L. Martínez-Rodríguez, A. W. Kleij, J. Am. Chem. Soc. 2016, 138, 14194; b) J. Xie, W. Guo, A. Cai, E. C. Escudero-Adan, A. W Kleij, Org. Lett. 2017, 19, 6388; c) M. Quan, N. Butt, J. Shen, K. Shen, D. Liu, W. Zhang, Org. Biomol. Chem. 2013, 11, 7412.

[30] a) B. M. Trost, A. Aponick, J. Am. Chem. Soc. 2006, 128, 3931; b) B. M. Trost, A. Aponick, B. N. Stanzl, Chem. Eur. J. 2007, 13, 9547; c) B. M. Trost, B. M. O'Boyle, W. Torres, M. K. Ameriks, Chem. Eur. J. 2011, 17, 7890.

[31] Y. J. Zhang, J. H. Yang, S. H. Kim, M. J. Krische, J. Am. Chem. Soc. 2010, $132,4562$.

[32] A. Khan, S. Khan, I. Khan, C. Zhao, Y. Mao, Y. Chen, Y. J. Zhang, J. Am. Chem. Soc. 2017, 139, 10733.

[33] W. Guo, R. Kuniyil, J. E. Gómez, F. Maseras, A. W. Kleij, J. Am. Chem. Soc. 2018, 140, 3981.

[34] T. Bando, H. Harayama, Y. Fukazawa, M. Shiro, K. Fugami, S. Tanaka, Y. Tamaru, J. Org. Chem. 1994, 59, 1465.

[35] a) L. Yang, A. Khan, R. Zheng, L. Y. Jin, Y. J. Zhang, Org. Lett. 2015, 17, 6230; b) A. Khan, J. Xing, J. Zhao, Y. Kan, W. Zhang, Y. J. Zhang, Chem Eur. J. 2015, 21, 120; c) A. Khan, R. Zheng, Y. Kan, J. Ye, J. Xing, Y. J. Zhang, Angew. Chem. Int. Ed. 2014, 53, 6439; d) A. Khan, L. Yang, J. Xu L. Y. Jin, Y. J. Zhang, Angew. Chem. Int. Ed. 2014, 53, 10416; e) A. Bayer, U. Kazmaier, J. Org. Chem. 2014, 79, 8498; f) I. Khan, C. Zhao, Y. J. Zhang Chem. Commun. 2018, 54, 4708.

[36] A. Khan, Y. J. Zhang, Synlett 2015, 26, 853

[37] a) L.-C. Yang, Z.-Q. Rong, Y.-N. Wang, Z. Y. Tan, M. Wang, Y. Zhao, Angew. Chem. Int. Ed. 2017, 56, 2927; b) Z.-Q. Rong, L.-C. Yang, S. Liu Z. Yu, Y.-N. Wang, Z. Y. Tan, R.-Z. Huang, Y. Lan, Y. Zhao, J. Am. Chem. Soc. 2017, 139, 15304. Similar to these approaches, Guo and co-workers have reported the [5+3] cycloaddition reactions between VCCs and azomethine imines producing eight-membered heterocycles, see: c) C Yuan, Y. Wu, D. Wang, Z. Zhang, C. Wang, L. Zhou, C. Zhang, B. Song, H. Guo, Adv. Synth. Catal. 2018, 360, 652.

[38] S. Singha, T. Patra, C. G. Daniliuc, F. Glorius, J. Am. Chem. Soc. 2018, 140,3551

[39] Note that similar to the work of Zhao and Glorius, Shibata also reported the formation of $\mathrm{CF}_{3}$-substituted nine-membered heterocycles: $\mathrm{P}$. Das, $\mathrm{S}$. Gondo, P. Nagender, H. Uno, E. Tokunaga, N. Shibata, Chem. Sci. 2018, 9, 3276.

[40] K. Komatsuki, Y. Sadamitsu, K. Sekine, K. Saito, T. Yamada, Angew. Chem. Int. Ed. 2017, 56, 11594. 
[41] Y.-A. Guo, T. Liang, S. W. Kim, H. Xiao, M. J. Krische, J. Am. Chem. Soc. 2017, 139, 6847.

[42] a) M. Moselage, J. Li, L. Ackermann, ACS Catal. 2016, 6, 498-525; b) K. Gao, N. Yoshikai, Acc. Chem. Res. 2014, 47, 1208-1219; c) Y. Hu, B. Zhou, C. Wang, Acc. Chem. Res. 2018, 51, 816-827; d) W. Liu, L. Ackermann, ACS Catal. 2016, 6, 3743-3752.

[43] a) S.-S. Zhang, J.-Q. Wu, Y.-X. Lao, X.-G. Liu, Y. Liu, W.-X. Lv, D.-H. Tan, Y.-F. Zeng, H. Wang, Org. Lett. 2014, 16, 6412; b) S.-S. Zhang, J.-Q. Wu, X. Liu, H. Wang, ACS Catal. 2015, 5, 210.

[44] a) S. Sharma, S. H. Han, Y. Oh, N. K. Mishra, S. Han, J. H. Kwak, S.-Y. Lee, Y. H. Jung, I. S. Kim, J. Org. Chem. 2016, 81, 2243; b) S. Sharma, Y. Shin, N. K. Mishra, J. Park, S. Han, T. Jeong, Y. Oh, Y. Lee, M. Choi, I. S. Kim, Tetrahedron 2015, 71, 2435.

[45] a) H. Wang, M. M. Lorion, L. Ackermann, Angew. Chem. Int. Ed. 2017, 56, 6339; b) Q. Lu, F. J. R. Klauck, F. Glorius, Chem. Sci. 2017, 8, 3379.

[46] X. Jiang, J. Chen, W. Zhu, K. Cheng, Y. Liu, W.-K. Su, C. Yu, J. Org. Chem. 2017, 82, 10665.

[47] H. Wang, M. M. Lorion, L. Ackermann, ACS Catal. 2017, 7, 3430.

[48] a) K. Ohe, H. Matsuda, T. Ishihara, S. Ogoshi, N. Chatani, S. Murai, J. Org. Chem. 1993, 58, 1173; b) R. Shintani, K. Moriya, T. Hayashi, Chem. Commun. 2011, 47, 3057.

[49] Y. Hara, S. Onodera, T. Kochi, F. Kakiuchi, Org. Lett. 2015, 17, 4850.

[50] R. Ninokata, T. Yamahira, G. Onodera, M. Kimura, Angew. Chem. Int. Ed. 2017, 56, 208

[51] a) C. Darcel, C. Bruneau, P. H. Dixneuf, J. Chem. Soc., Chem. Commun. 1994, 1845; b) C. Darcel, S. Bartsch, C. Bruneau, P. H. Dixneuf, Synlett 1994, 457; c) C. Darcel, C. Bruneau, P. H. Dixneuf, Synlett 1996, 218.

[52] C. Darcel, C. Bruneau, M. Albert, P. H. Dixneuf, Chem. Commun. 1996, 919

[53] X. Tang, S. Woodward, N. Krause, Eur. J. Org. Chem. 2009, 2836.

[54] a) L. Tian, L. Gong, X. Zhang, Adv. Synth. Catal. 2018, 360, 2055; b) G. Hattori, A. Yoshida, Y. Miyake, Y. Nishibayashi, J. Org. Chem. 2009, 74 7603.

[55] H. Wang, F. Pesciaioli, J. C. A. Oliveira, S. Warratz, L. Ackermann, Angew. Chem. Int. Ed. 2017, 56, 15063.

[56] J. Sauer, K. K. Mayer, Tetrahedron Lett. 1968, 9, 319.

[57] a) Y. Park, J. Heo, M.-H. Baik, S. Chang, J. Am. Chem. Soc. 2016, 138, 14020; b) Y. Park, K. T. Park, J. G. Kim, S. Chang, J. Am. Chem. Soc. 2015, $137,4534$.

[58] a) Y. Park, S. Jee, J. G. Kim, S. Chang, Org. Process Res. Dev. 2015, 19, 1024; b) J. Park, S. Chang, Angew. Chem. Int. Ed. 2015, 54, 14103; c) J. Park, J. Lee, S. Chang, Angew. Chem. Int. Ed. 2017, 56, 4256; d) G. N. Hermann, C. Bolm, ACS Catal. 2017, 7, 4592; e) S.-B. Wang, Q. Gu, S.-L. You, Organometallics 2017, 36, 4359; f) A. E. Hande, K. R. Prabhu, J. Org Chem. 2017, 82, 13405; g) H. Cheng, J. G. Hernández, C. Bolm, Adv Synth. Catal. 2018, 360, 1800; h) A. Mishra, U. Mukherjee, T. K. Vats, I. Deb, J. Org. Chem. 2018, 83, 3756; i) X. Wang, S. Song, N. Jiao, Chin. J. Chem. 2018, 36, 213.

[59] a) Y. Liang, Y.-F. Liang, C. Tang, Y. Yuan, N. Jiao, Chem. Eur. J. 2015, 21, 16395; b) R. Mei, J. Loup, L. Ackermann, ACS Catal. 2016, 6, 793; c) B. Jeon, U. Yeon, J.-Y. Son, P. H. Lee, Org. Lett. 2016, 18, 4610; d) N. K. Mishra, Y. Oh, M. Jeon, S. Han, S. Sharma, S. H. Han, S. H. Um, I. S. Kim, Eur. J. Org. Chem. 2016, 2016, 4976; e) M. Jeon, N. K. Mishra, U. De, S. Sharma, Y. Oh, M. Choi, H. Jo, R. Sachan, H. S. Kim, I. S. Kim, J. Org Chem. 2016, 81, 9878; f) W. Zhang, H. Deng, H. Li, Org. Chem. Front. 2017 4, 2202; g) H. Deng, H. Li, W. Zhang, L. Wang, Chem. Commun. 2017, 53, 10322. h) Y. Zhou, O. D. Engl, J. S. Bandar, E. D. Chant, S. L. Buchwald, Angew. Chem. Int. Ed. 2018, 57, 6672.

[60] a) F. Wang, H. Wang, Q. Wang, S. Yu, X. Li, Org. Lett. 2016, 18, 1306; b) J. Wang, S. Zha, K. Chen, F. Zhang, C. Song, J. Zhu, Org. Lett. 2016, 18, 2062; c) X. Wang, A. Lerchen, F. Glorius, Org. Lett. 2016, 18, 2090; d) H. Wang, M. M. Lorion, L. Ackermann, Angew. Chem. Int. Ed. 2016, 55, 10386; e) X. Wu, S. Sun, S. Xu, J. Cheng, Adv. Synth. Catal. 2018, 360, 1111.

[61] Q. Wang, F. Wang, X. Yang, X. Zhou, X. Li, Org. Lett. 2016, 18, 6144.

[62] a) J. Xia, X. Yang, Y. Li, X. Li, Org. Lett. 2017, 19, 3243; b) Y. Chen, R. Zhang, Q. Peng, L. Xu, X. Pan, Chem. Asian. J. 2017, 12, 2804.

[63] K. S. Halskov, H. S. Roth, J. A. Ellman, Angew. Chem. Int. Ed. 2017, 56, 9183.
[64]J. Huang, Y. Huang, T. Wang, Q. Huang, Z. Wang, Z. Chen, Org. Lett. 2017, $19,1128$.

[65] F. Wang, L. Jin, L. Kong, X. Li, Org. Lett. 2017, 19, 1812.

[66] a) H. Wang, G. Tang, X. Li, Angew. Chem. Int. Ed. 2015, 54, 13049; b) N. Barsu, M. A. Rahman, M. Sen, B. Sundararaju, Chem. Eur. J. 2016, 22, 9135; c) P. W. Tan, A. M. Mak, M. B. Sullivan, D. J. Dixon, J. Seayad, Angew. Chem. Int. Ed. 2017, 56, 16550; d) Y. Liu, F. Xie, A.-Q. Jia, X. Li, Chem. Commun. 2018, 54, 4345.

[67] a) V. Bizet, L. Buglioni, C. Bolm, Angew. Chem. Int. Ed. 2014, 53, 5639; b) V. Bizet, C. Bolm, Eur. J. Org. Chem. 2015, 2015, 2854.

[68] C. L. Zhong, B. Y. Tang, P. Yin, Y. Chen, L. He, J. Org. Chem. 2012, 77, 4271.

[69] A. K. Ghosh, M. Brindisi, J. Med. Chem. 2015, 58, 2895

[70] J. D. Weaver, A. Recio III; A. J. Grenning, J. A. Tunge. Chem. Rev. 2011 $111,1846$.

[71]T.-R. Li, Y.-N. Wang, W.-J. Xiao, L.-Q. Lu, Tetrahedron Lett. 2018, 59, 1521

[72] B. D. W. Allen, C. P. Lakeland, J. P. A. Harrity, Chem. Eur. J. 2017, 23 13830.

[73] Q. Lu, S. Cembellín, S. Greßies, S. Singha, C. G. Daniliuc, F. Glorius. Angew. Chem. Int. Ed. 2018, 57, 1399.

[74] For some recent examples: a) G. Dong, P. Teo, Z. K. Wickens, R. H. Grubbs, Science 2011, 333, 1609; b) D. F. Chen, Z. Y. Han, X. L. Zhou, L. Z. Gong, Acc. Chem. Res. 2014, 47, 2365. For a cooperative catalytic system, please refer to ref. 38 as an example. For a recent review on heteromultimetallic catalysis: c) M. M. Lorion, K. Maindan, A. R. Kapdi, L. Ackermann, Chem. Soc. Rev. 2017, 46, 7399 


\section{Entry for the Table of Contents:}

\section{MINIREVIEW}

How to transform a ring: Functionalized cyclic carbonates and related heterocycles find increasing synthetic utility using predominantly transition metal catalysis. In particular, vinyl- and alkynyl-substituted substrates have been at the forefront of these developments with decarboxylative approaches being prevalent. An overview of recent developments towards new regio- and stereoselective transformations useful in fine chemical and pharmarelevant synthesis are presented.

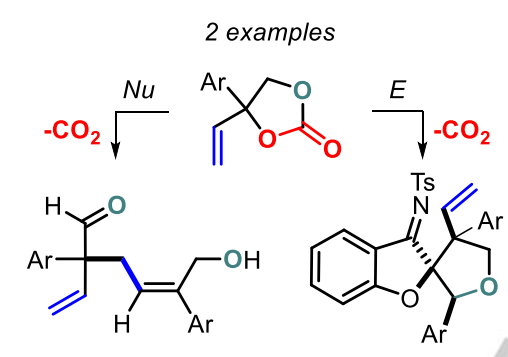

Wusheng Guo, * José Enrique Gómez, Àlex Cristòfol, Jianing Xie, and Arjan W. Kleij ${ }^{*}$

Page No. - Page No.

Catalytic Transformations of Functionalized Cyclic Organic Carbonates 